\title{
Seismic behavior of a thatched house at Minehama village in Akita, Japan
}

\author{
K. Ueta, C. Cuadra, K. Tokeshi \& M. B. Karkee \\ Graduate School of System Science and Technology, \\ Department of Architecture and Environment Systems, \\ Akita Prefectural University, Tsuchiya, Honjo, Akita, Japan
}

\begin{abstract}
Old traditional wooden constructions in Japan are declared as buildings of cultural interest and therefore efforts are made to preserve these kinds of buildings. In this study, a traditional wooden structure is investigated to determine its dynamic characteristics and evaluate its seismic performance. The structure corresponds to a framed wooden construction with traditional connections between columns and beams. In general, nails are not used in these joints, and instead, the beam is narrowed at each end to be inserted into a hole cut in the column. This joint is known as a mortise-tenon joint. The end narrowed member of the beam is called the tenon, and the hole in the column is called the mortise. The joints are wedged to lock them in place. The modeling of this joint becomes a challenge since it does not correspond to a rigid joint of a common frame or to a hinge. The stiffness of this joint varies from the hinge to the perfect rigid joint. Therefore, the model used in this study is called a half rigid joint where the moment rotation relationship is specified for each beam end. Then, the dynamic analysis is performed to obtain the modes of vibration, and the results are compared with those obtained by means of the microvibration measurements. In general, good agreement was obtained between both results.

Keywords: thatched roof, seismic behaviour, wooden frame, micro vibration.
\end{abstract}

\section{Introduction}

Reed roofing was used in old traditional constructions in Japan, and some of them remain nowadays in rural areas. These buildings integrated into rural 
landscapes resemble the Edo period style (period in Japan from 1603 to 1867), as can be observed in figure 1 .

In the northern part of Akita Prefecture in Japan, a small settlement in Minehama village that consists of four buildings with reed roofing was abandoned due to the migration of their inhabitants. Then, the community began activities to preserve these buildings in the year 2000. Now, the buildings are used for some cultural activities like lectures, seminars or to experience the old way of living in these traditional buildings.

On the other hand, the region is a zone of great seismic activity that can affect the integrity of the buildings. In this sense, this research is an attempt to evaluate the dynamic characteristics of buildings taking into account the complexity of structural modelling of joints. The analysis is performed by means of the finite element method. Also, in-situ measurements of micro vibration of one building were done to estimate the modes of vibrations and compare these results with those obtained analytically.

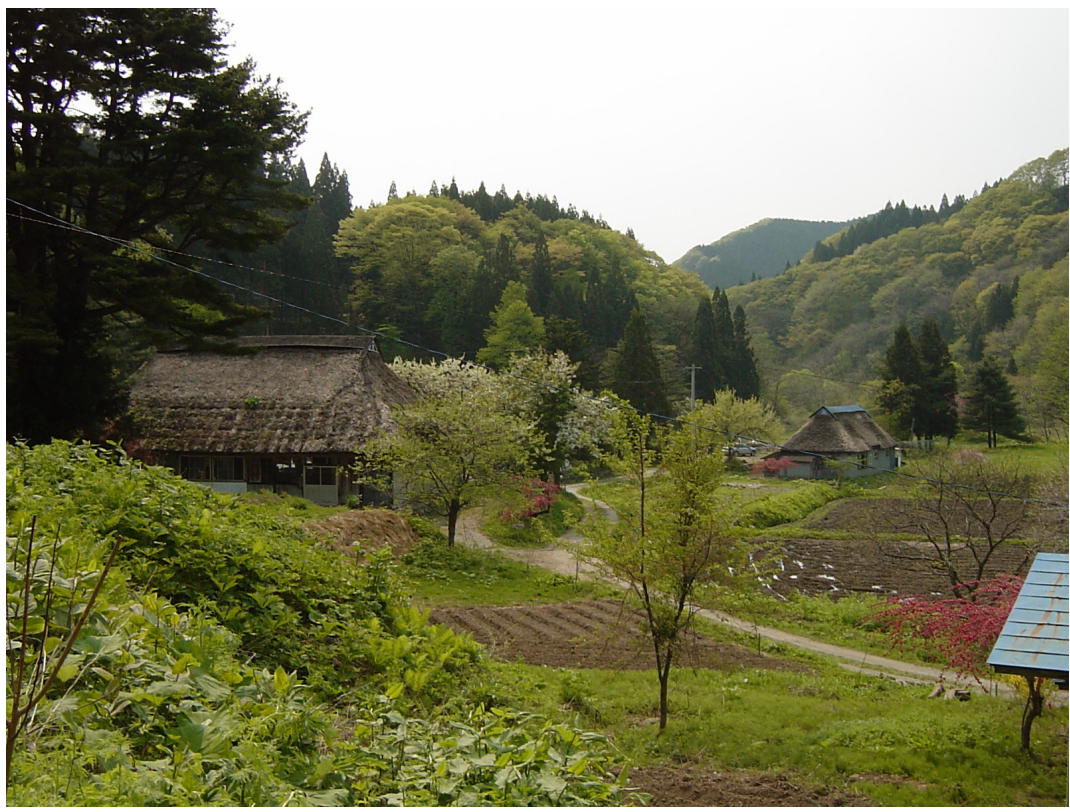

Figure 1: Rural landscape with reed roofing buildings.

\section{Measurements of the micro vibration of the building}

One of the buildings, called building $\mathrm{C}$, was chosen to perform the micro vibration measurements and the correspondent analysis. Details of this selected structure are shown in figure 2 . The dimensions of this building are $9.40 \mathrm{~m}$ wide and $20.30 \mathrm{~m}$ long. The interior of the building consists of the earthen floor where the kitchen and tools store are located, and also there is a part of Japanese tatami 


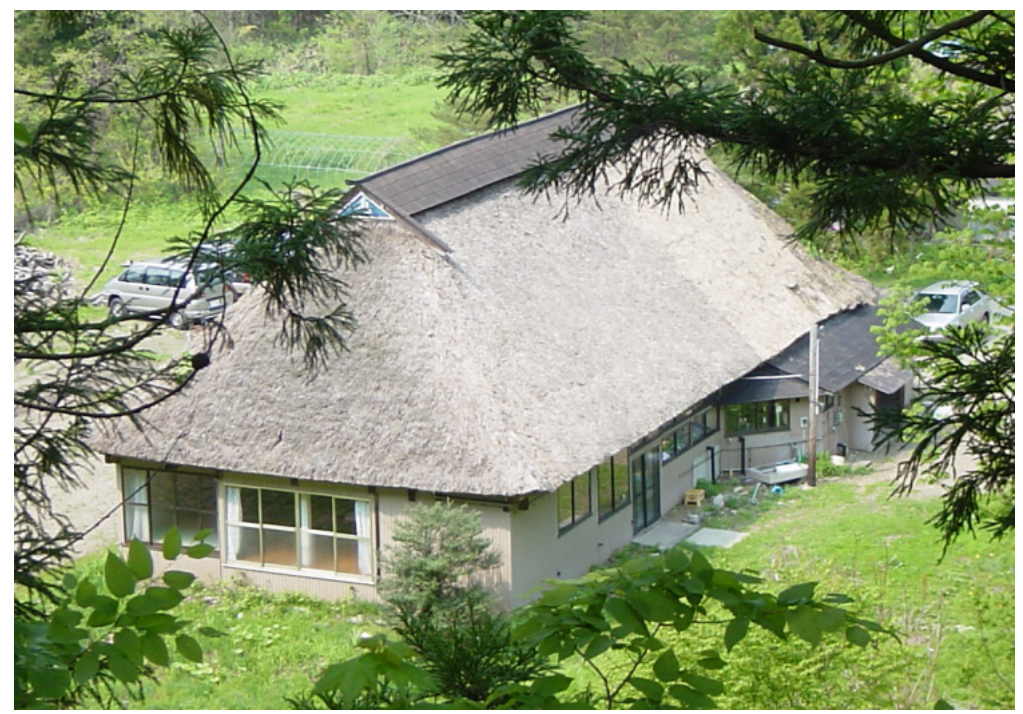

Figure 2: $\quad$ Detail of $\mathrm{C}$ building.

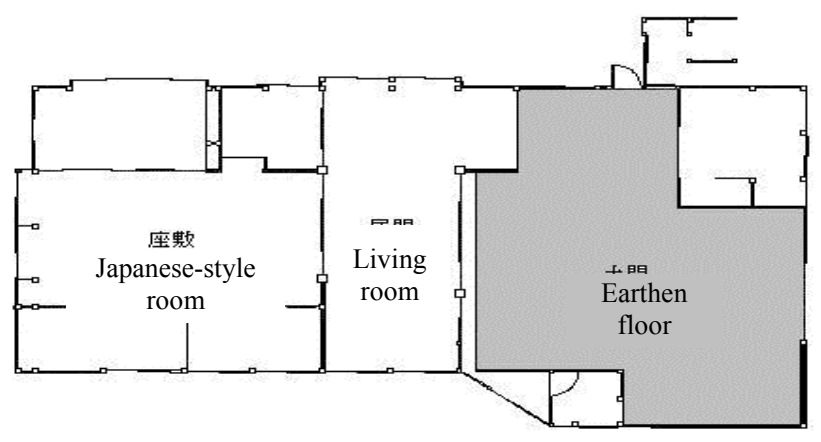

Figure 3: $\quad$ Plan view of $\mathrm{C}$ building.

mat floor for a living space and bedroom. The structural system is a frame that permits the creation of a large inner space, as can be observed in figure 3 .

The location of the sensors for the microtremor measurements are indicated in figure 4. Points 1 and 2 are located on the first floor level. Points 3, 4, 5 and 6 are located at the dormer level and points 7, 8, 9 and 10 are located at the level of the highest horizontal member of the roof truss. The two components of the horizontal vibration were measured (NS directions and EW direction) at each point of measurement. All points of measurement were measured simultaneously during 
500 seconds. Then, stationary portions of the records were selected to perform the Fourier analysis that permits to estimate the natural period of vibration of the structure. Transfer functions were calculated for all upper points with respect to the first level (Point 2).
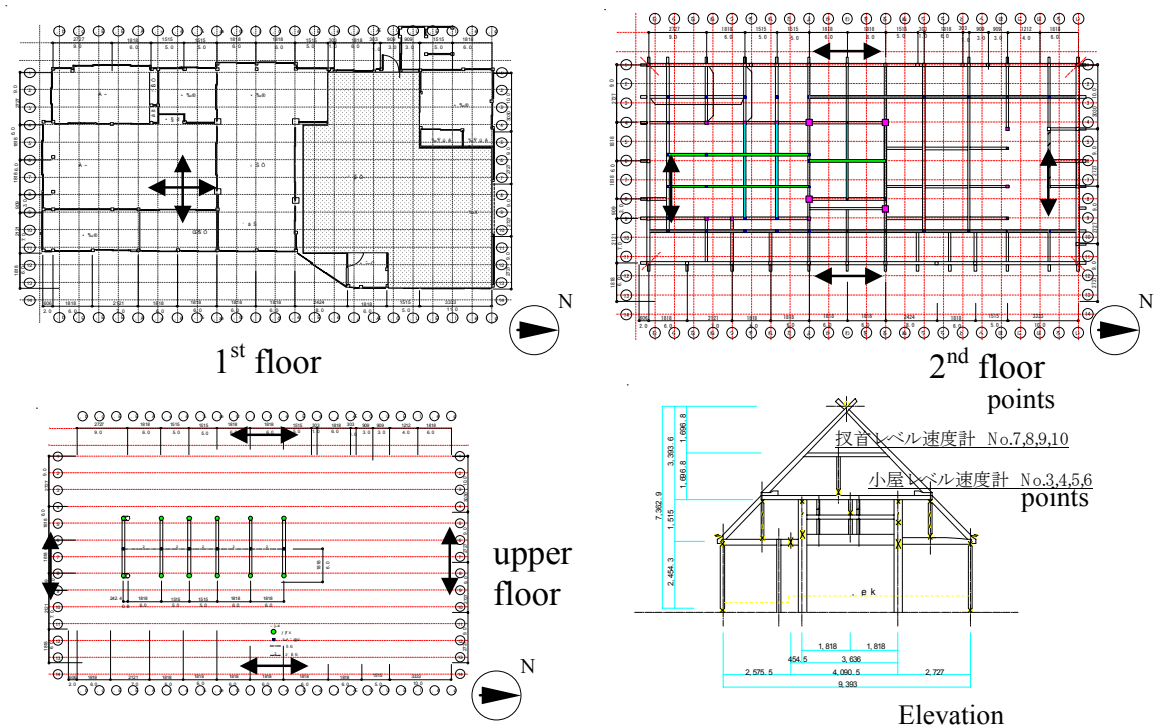

Figure 4: Location of the points of microtremor measurements.
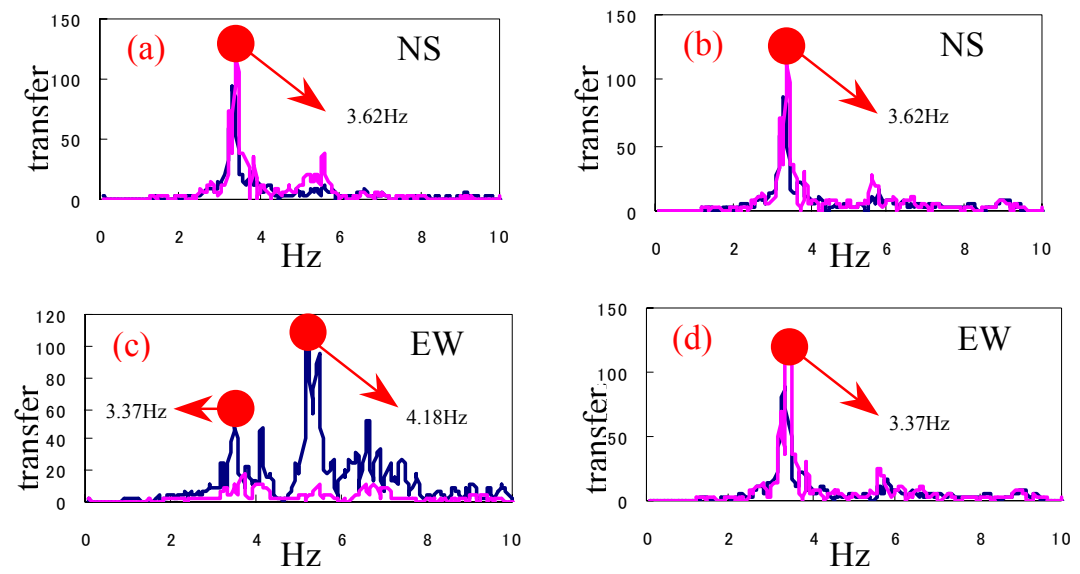

Figure 5: Horizontal transfer functions from microtremor measurements. 
The results of the Fourier analysis are shown in figure 5. It can be observed from figure 5(a) and (b) that the value of the predominant frequency in the NS direction is $3.62 \mathrm{~Hz}$. In case of the EW direction, a clear peak at $3.37 \mathrm{~Hz}$ is shown in figures $5(\mathrm{c})$ and (d). Also a peak at $4.18 \mathrm{~Hz}$ was detected that corresponds to torsional mode.

\section{Theoretical analysis}

The structure was analysed using a 3-D finite element model. Also, the contribution of the walls was considered in the model. In the first attempt, lower frequencies compared with those of microtremor measurements were obtained when considering only the frame structure. Then, a better agreement with values of frequencies was obtained when considering the contribution of the wall to the lateral stiffness. The stiffness of the walls was evaluated by means of an empirical formula and equating it with the elastic deformation that takes into account the contribution of bending and shear stresses. Results of the modal analysis show that, the first mode is the normal mode in the EW direction, the second mode is the normal mode in the NS direction, and the third mode is the torsional mode. The horizontal normal modes of vibration can be appreciated in figure 6. The torsional mode of vibration is shown in figure 7. Table 1 shows a comparison of analysis and microtremors results. It can be said that both results agreed well, and the FEM simulation verifies mode vibrations (including the torsional mode) assumed from transfer function of microtremor measurements.
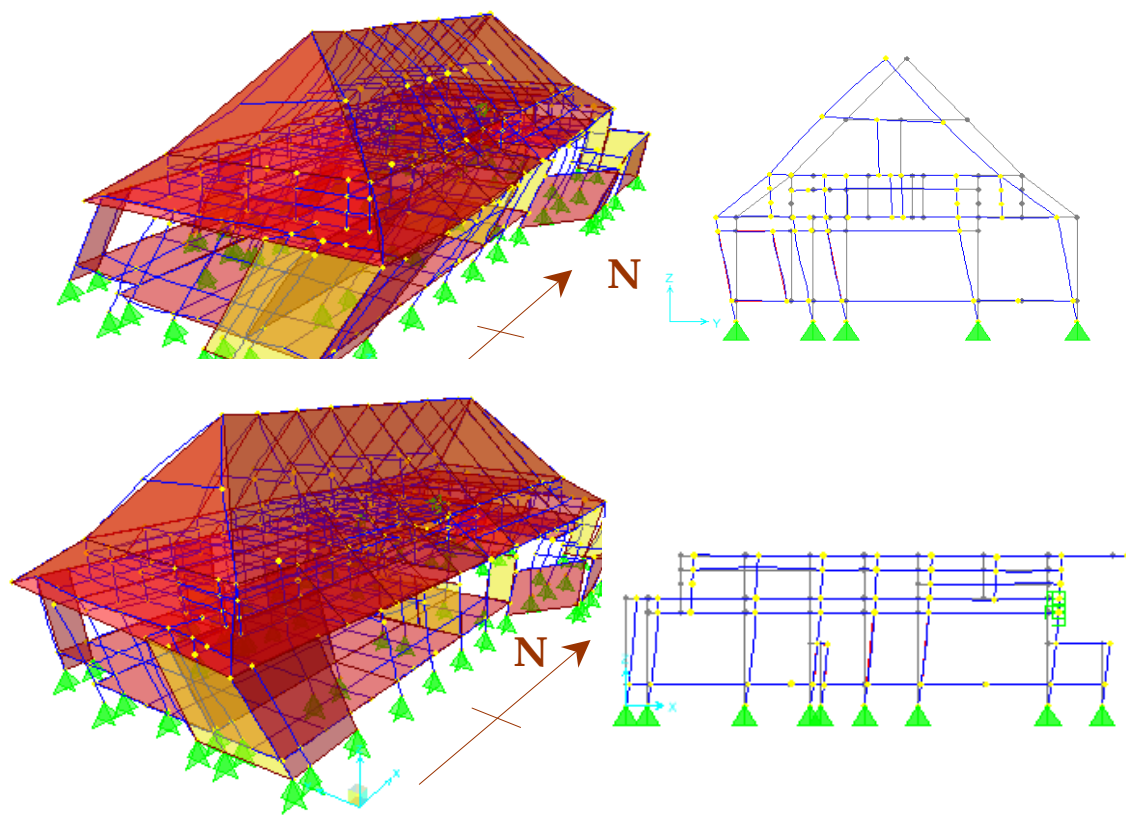

Figure 6: Normal horizontal modes of vibration. 

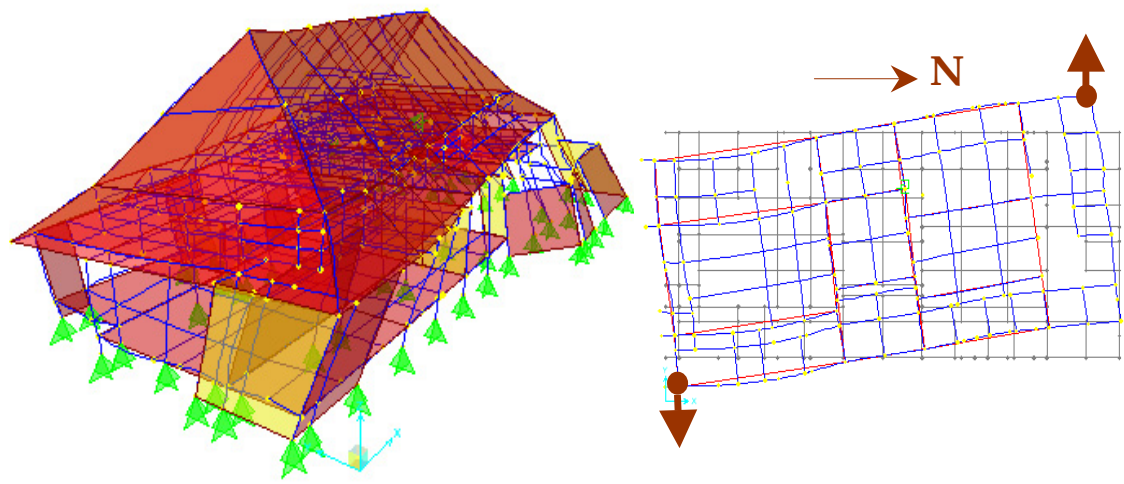

Figure 7: Torsional mode of vibration.

Table 1: Comparison of analytical results and microtremor measurements results.

\begin{tabular}{|c|c|c|}
\hline Mode of vibration & $\begin{array}{c}\text { Microvibration } \\
\text { measurement } \\
(\mathrm{Hz})\end{array}$ & $\begin{array}{c}\text { FEM analysis } \\
(\mathrm{Hz})\end{array}$ \\
\hline Horizontal EW & 3.37 & 3.44 \\
\hline Horizontal NS & 3.62 & 3.60 \\
\hline Torsional & 4.18 & 4.39 \\
\hline
\end{tabular}

\section{Conclusions}

Microtremor measurements have been successfully employed to determine the dynamic characteristics of traditional Japanese wooden structure. In addition to the normal horizontal modes of vibration in the two principal directions, the torsional mode of vibration was detected by microtremor measurements and verified by dynamic analysis using finite element method.

Due to the large dimension in the NS direction, torsional mode appears in transverse EW direction. Here, it is important to point out that these behaviours are detected only by in-situ measurements or by a three dimensional dynamic analysis, indicating the importance of considering 3D systems.

The reliability of microtremor measurements as a tool for assessing dynamic characteristics of buildings were validated with the dynamic analytical results obtained from finite element method. 
Structural Studies, Repairs and Maintenance of Heritage Architecture X 673

\section{References}

[1] K. Ueta, K. Tokeshi, C. Cuadra and M.B. Karkee. A study on earthquake resistance of traditional thatched house at Minehama village in Akita. Summaries of Technical Papers of Annual Meeting 2006, AIJ, Paper No. 20143. 